\title{
REDUCED RESILIENCE AND OTHER PREDISPONENT FACTORS FOR FUNCTIONAL NEUROLOGICAL DISORDERS
}

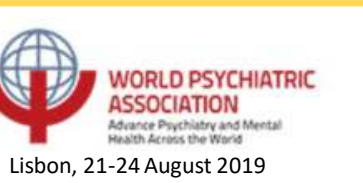

\section{ObJectives:}

To identify the vulnerability factors for the development and maintenance of functional neurological disorders.

\section{BACKGROUND AND AIMS:}

Patients with functional neurological disorders have marked dysfunctionality and represent a challenge in terms of knowledge of etiopathogenic mechanisms and, consequently, in the therapeutic approach. Different forms of functional neurological disorders may be associated with different personality traits.

We intend to know the role of resilience and associated factors in functional neurological disorders.

\section{MATERIALS AND METHODS:}

Brief review of the English literature published in the last four years, using the Medline ${ }^{\circledR}$ database. Key-words: "resilience" and "functional neurological disturbance". Articles were selected based on the content of your abstract and its relevance.

\section{RESULTS:}

Different forms of functional neurological disorders may be associated with different personality traits.

We know that extroversion, through the tendency for more social interactions, positive affection and social support, is associated with a higher resilience and lower risk of psychopathology.

Studies show that men use avoidant coping more often, so women seem to have higher levels of resilience.

Development and maintenance of functional neurological disorders have been associated with:

- reduced resilience;

- dysfunctional personality traits;

- neuroticism;

- alexithymia;

- low insight;

- depression / anxiety.
Resilience is a dynamic construct that involves the ability to adapt positively and recover from stress or adversity.

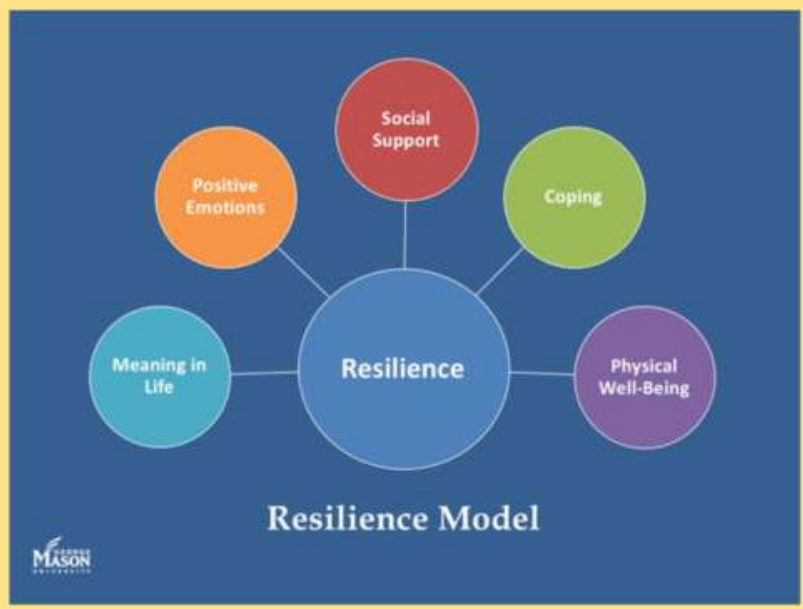

Fig. 1 George Mason University's Resilience Model.

\section{ConCLusions:}

Patients with reduced resilience develop maladaptive coping mechanisms, with an increased response to stress, which predisposes to the development of functional neurological disorders and/or contributes to its perpetuation and poor prognosis.

\section{REFERENCES:}

Jalilianhasanpour R et al. Resilience linked to personality dimensions, alexithymia and affective symptoms in motor functional neurological disorders. J Psychosom Res. 2018 Apr;107:55-61. Park SH et al. Resilience is decreased in irritable bowel syndrome and associated with symptoms and cortisol response. Neurogastroenterol Motil. 2018 Jan;30(1). 